Check for updates

Cite this: RSC Adv., 2017, 7, 45911

Received 7th August 2017

Accepted 22nd September 2017

DOI: $10.1039 / c 7 r a 08717 a$

rsc.li/rsc-advances

\section{Seed geometry and hydrogen bonding dependent plasmonic tuning of silver nanocrystals in a citrate- hydrazine matrix and SERS spectroscopic detection of chromium $\uparrow$}

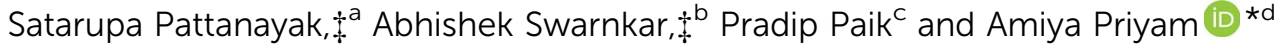

By employing a 'mild stabilizer-mild reductant' system, a seed-mediated synthesis of tunable anisotropic and plasmonic silver nanocrystals (NCs) has been developed. Differently shaped seed NCs were synthesized using citrate and hydrazine hydrate as stabilizer and reductant respectively, and the same reagent system was retained for the subsequent overgrowth process as well. Spherical seed NCs always resulted in red-shifted plasmon peaks of the overgrown nanocrystals. However, we found that anisotropic seed NCs may cause either a red-shift or a blue-shift of the plasmon peak depending on the geometry of the seed NCs. Plate-like seed NCs result in red-shifted surface plasmon bands as a consequence of structural transformation from pentagonal to hexagonal plate-like structures. Second derivative FTIR and Raman spectroscopy revealed that the anisotropic overgrowth of the seed NCs is directed by the stabilizer-reductant i.e., citrate-hydrazine, hydrogen bonding network. As the concentration of hydrazine increases, the $\mathrm{H}$-bonded network is strengthened and the plasmon peak shows a gradual red-shift ( $500 \mathrm{~nm} \rightarrow 615 \mathrm{~nm}$ ). In contrast, a pyramid-like seed causes a blue shift of the plasmon peak ( $790 \mathrm{~nm} \rightarrow 775 \mathrm{~nm}$ ), attributed to the loss of structural anisotropy of the pyramid like nanostructures. Based on the interaction of these NCs with inorganic oxoanions, a rapid and sensitive SERS-detection method for $\mathrm{Cr}(\mathrm{III})$ and $\mathrm{Cr}(\mathrm{VI})$ species has been developed with a limit of detection of 30 and $40 \mathrm{ppb}$, respectively. The simplicity is underscored as the detection method works under nonresonant conditions and in the solution phase without any "SERS tags".
\end{abstract}

\section{Introduction}

Plasmonic nanocrystals (NCs) have attracted special attention in material science due to their unique chemical and physical properties $^{\mathbf{1 - 5}}$ including optical, electronic, magnetic, and catalytic properties. Because of these properties, plasmonic NCs have found applications in fields as diverse as bio-imaging, ${ }^{6}$ cancer therapy, ${ }^{7-9}$ antibacterial medicine, ${ }^{10-12} \quad \mathrm{H}_{2}$ production, ${ }^{13}$ sensors, ${ }^{\mathbf{1 4 - 1 7}}$ plasmonic, electrochemical and electronic devices, ${ }^{18-20}$ spectroscopic measurements such as surface enhanced Raman spectroscopy (SERS) ${ }^{21,22}$ and so on. Both the size and shape of the plasmonic NCs provide useful control over the properties mentioned above. For example, anisotropic (non-

\footnotetext{
${ }^{a}$ Dept. of Applied Chemistry, Birla Institute of Technology, Mesra, Ranchi-835215, India ${ }^{5}$ Indian Institute of Science Education and Research, Pune-411008, India ${ }^{c}$ Materials Engineering, Nanoscience and Technology, School of Engineering Sciences and Technology, University of Hyderabad, Hyderabad-500046, India

${ }^{d}$ Dept. of Chemistry, Central University of South Bihar, Gaya-823001, India. E-mail: apriyam@cub.ac.in; amiya.priyam@gmail.com

$\dagger$ Electronic supplementary information (ESI) available. See DOI: $10.1039 / \mathrm{c} 7 \mathrm{ra} 08717 \mathrm{a}$

¥ The two authors (AS \& SP) have contributed equally.
}

spherical) shapes have stronger surface plasmon resonance (SPR) absorption than their spherical counterpart, leading to increased detection sensitivity. ${ }^{18}$ Anisotropic NCs show better and versatile tunability of SPR peaks spanning visible to near-IR region that includes the biologically transparent window, i.e., 650-1200 nm. ${ }^{23}$ This is in stark contrast to the limited SPR tunability achieved in spherical NCs. On increasing the size of gold and silver nanocrystals from $10 \mathrm{~nm}$ to $100 \mathrm{~nm}$, the SPR peak shows a small red shift of about $60-80 \mathrm{~nm}$ in the visible region. ${ }^{24,25}$ Anisotropic NCs also generate enhanced electromagnetic field which in turn can enhance scattering of light and Raman signal of the molecule present on the surface. ${ }^{26}$ In general, chemical reduction method which includes seed mediated approach is the most common methodology of synthesis of anisotropic, plasmonic NCs. ${ }^{28-30}$ Anisotropic silver and gold NCs of different sizes and shapes with tunable SPR wavelength have been synthesized over the years and in most of the cases, strong reducing agent such as sodium borohydride has been used for preparation of spherical seed NCs. ${ }^{24-26,28-30}$ Subsequently, in the second step, mild reducing agents, such as ascorbic acid, ${ }^{27,28,31,32}$ citrate 33 along with shape directing ligands $\mathrm{s}^{32-36}$ are used to induce anisotropic overgrowth of the 
NCs. Besides, photo-induced anisotropic growth over spherical seed $\mathrm{NCs}^{30,37-39}$ is also a well-known method. It was also demonstrated by Mirkin et al. ${ }^{39,40}$ that both photochemical and thermal control mutually contribute to the growth of prismshaped anisotropic Ag NCs in the seed mediated synthesis.

All the syntheses mentioned above involve preparation of seed NCs which are predominantly spherical in shape. Little is known about how the shape of seed NCs would influence the growth process and how would the structural and plasmonic properties evolve. ${ }^{41}$ It is also important to investigate the effect of the environment for the seeded growth which includes temperature and reagent concentrations of growth media. From an academic point of view, a better understanding of seed-mediated growth process is needed which will enable us to work out the entire evolutionary pathway of structural and optical properties in such anisotropic NCs. It will also help synthesize NCs with desired plasmonic properties for an intended application.

In this work, seed NCs of varying shapes (nanospheres, nanoplates, nanopyramids) have been prepared following the aqueous approach reported by us previously. ${ }^{23}$ These NCs have been subsequently used as nucleation centres to overgrow larger NCs, with tunable structural and plasmonic feature, to comprehend the role of seed anisotropy in subsequent crystal growth and change in plasmonic properties using the same citrate-hydrazine matrix. While spherical seeds always lead to a red shifted SPR wavelength, anisotropic seeds can lead to either blue shift or red shift in SPR wavelength. Depending upon the exact shape of seed NCs (plate-like or pyramid-like). Moreover, to decipher the role of growth environment, we show that the temperature during the seeded growth also plays a crucial role in determining the degree of crystal anisotropy and SPR tunability. To the best of our knowledge, this is a unique study of its kind and it opens new vistas for the fabrication of anisotropic NCs with controlled plasmonic and structural features.

Further, we present the application of anisotropic Ag NCs in SERS based detection of chromium, one of the most common contaminant of ground water, in both of its oxidation forms viz. $\mathrm{Cr}(\mathrm{III})$ and $\mathrm{Cr}$ (VI). Till date, mostly silver and gold nanocrystals of spherical shape have been used for the detection of such metal ions. ${ }^{42-45}$ Amongst these, there are only a few reports on the SERS-based detection of chromium ${ }^{45}$ and most of them employ specific molecules as "SERS tags". Here, we demonstrate a simplified approach for SERS-based detection of chromium in both of its most common oxidation states, $\mathrm{Cr}(\mathrm{III})$ and $\mathrm{Cr}(\mathrm{VI})$, with a detection limit of 30 and $40 \mathrm{ppb}$ respectively. The work is significant as such SERS-detection sensitivity has been achieved under non-resonant condition using colloidal, anisotropic silver NCs without any Raman reporter molecules or SERS tags. The detection method also becomes more economical as silver has greater Raman efficiency than that of $\mathrm{Au}$ and is forty times more cost-effective in comparison to $\mathrm{Au}^{23}$

\section{Experimental}

\section{Materials}

Silver nitrate $(\geq 99.5 \%)$, trisodium citrate dihydrate $(\geq 99 \%)$, hydrazine hydrate solution (78-82\%), potassium dichromate
( $\geq 99 \%$ ), chromium(III) oxide (99.9\%). All the chemicals were purchased from Sigma Aldrich and were used as received without any further purification.

\section{Methods}

Synthesis of seed NCs of different shapes. To initiate, seven sets of silver NCs were prepared by taking seven different seed NCs. Silver NCs of different shapes namely spherical, plate-like, pyramid-like, were synthesized simply by varying the reaction parameters which include hydrazine concentration [Hyd], $\mathrm{pH}$ and temperature as described in our previous work. ${ }^{23}$ Briefly, $\mathrm{AgNO}_{3}(1 \mathrm{mM}, 10 \mathrm{ml})$ and citrate $(80 \mathrm{mM}, 0.5 \mathrm{ml})$ solution were mixed with constant stirring. Subsequently, $2.0 \mathrm{ml}$ of hydrazine hydrate of varying concentration were added under different conditions of temperature and $\mathrm{pH}$. The synthesis of Ag-412 spherical seed NCs was carried out by adding $2.5 \mathrm{mM}$ hydrazine to the abovementioned solution at $25{ }^{\circ} \mathrm{C}$ and at $\mathrm{pH}$ 7. Platelike Ag-550 NCs was synthesized by adding $40 \mathrm{mM}$ hydrazine to the abovementioned solution at $5{ }^{\circ} \mathrm{C} \mathrm{pH} 5$ and at $\mathrm{pH} 7 . \mathrm{Ag}-790$ NCs were prepared using $40 \mathrm{mM}$ hydrazine at $5{ }^{\circ} \mathrm{C}$ and $\mathrm{pH} 5$. These NCs were then used as seeds to overgrow bigger anisotropic NCs with tunable structural and plasmonic features.

Spherical NCs as seeds for the overgrowth. At first, the seeded growth was done by taking $5 \mathrm{ml}$ of as synthesized aqueous solution of spherical seed NCs (prepared at $\mathrm{pH} 7$, $\left.25{ }^{\circ} \mathrm{C},[\mathrm{Hyd}]=2.5 \mathrm{mM}\right)$. To understand the effect of $[\mathrm{Hyd}]$ on the seed mediated overgrowth, $2 \mathrm{ml}$ aqueous solution having different [Hyd]: $2.5 \mathrm{mM}, 5 \mathrm{mM}, 10 \mathrm{mM}$ and $20 \mathrm{mM}$, were added to four sets of same spherical seed NCs, separately. Further, $2 \mathrm{ml}$ of $\mathrm{Ag}^{+}$-citrate (molar ratio 1:4) solution were added in which $\mathrm{Ag}^{+}$concentration $\left(\left[\mathrm{Ag}^{+}\right]\right)$was of $1 \mathrm{mM}$ and UV-vis-NIR absorption spectra of the overgrown NCs were recorded.

\section{Anisotropic nanocrystals as seeds for the overgrowth}

Effect of [Hyd]. Six sets of aqueous solutions of different anisotropic seed synthesized above were used for seeded growth. In each set, $5 \mathrm{ml}$ of different seed solutions were taken and $2 \mathrm{ml}$ of aqueous $\mathrm{Ag}^{+}$-citrate (molar ratio $1: 4$ ) solution was added drop wise in which $\left[\mathrm{Ag}^{+}\right]$was $1 \mathrm{mM}$.

Effect of $\left[\mathrm{Ag}^{+}\right]$. The effect of $\left[\mathrm{Ag}^{+}\right]$on the crystal overgrowth was first studied by taking aqueous solution of same anisotropic seed NCs (synthesized at [Hyd] $=40 \mathrm{mM}$, at $\mathrm{pH} 7,25^{\circ} \mathrm{C}$ ) in six different set of growth in which the concentration of $\mathrm{Ag}^{+}$-Cit was varying. For that, $2 \mathrm{ml}$ of $\mathrm{Ag}^{+}$-citrate solution (fixed molar ratio of $1: 4)$ containing different $\left[\mathrm{Ag}^{+}\right](0.3 \rightarrow 0.4 \rightarrow 0.5 \rightarrow 0.6$ $\rightarrow 0.8 \rightarrow 1.0 \mathrm{mM}$ ) were added to $5 \mathrm{ml}$ of aqueous solution of chosen seed NC and six different sets of AIT NCs were obtained.

Effect of temperature. The effect of temperature was observed on a selected seed NCs prepared at $\mathrm{pH} 7,25^{\circ} \mathrm{C}$ and with [Hyd] $=$ $40 \mathrm{mM}$. The seeded growth was performed on the same seed at two different temperatures, $25{ }^{\circ} \mathrm{C}$ and $5{ }^{\circ} \mathrm{C}$ keeping all the reaction parameter same. In each case $2 \mathrm{ml}$ of $\mathrm{Ag}^{+}$-citrate solution (1:4 molar ratio, $\left[\mathrm{Ag}^{+}\right]$: $1 \mathrm{mM}$ ) was added then the solution was stirred for $30 \mathrm{~min}$.

Effect of shape. Two types of anisotropic seed NCs have been used one having plate like structure while the other having 
pyramid-like structure and they were made to overgrow bigger anisotropic NCs.

Nanoplates. $5 \mathrm{ml}$ of as synthesized aqueous solution of pentagonal nanoplates (prepared at $\mathrm{pH} 7,5^{\circ} \mathrm{C},[\mathrm{Hyd}]=40 \mathrm{mM}$ ) were taken as seed NCs and the overgrowth was performed at two different temperatures $\left(25^{\circ} \mathrm{C}\right.$ and $\left.5{ }^{\circ} \mathrm{C}\right)$ by addition of $2 \mathrm{ml}$ $\mathrm{Ag}^{+}$-citrate $(1: 4)$ mixture $\left(\left[\mathrm{Ag}^{+}\right]=1 \mathrm{mM}\right)$ and stirred for $30 \mathrm{~min}$.

Nanopyramids. $5 \mathrm{ml}$ of as synthesized aqueous solution of Ag nanopyramids (prepared at $\mathrm{pH} 5,5{ }^{\circ} \mathrm{C},[\mathrm{Hyd}]=40 \mathrm{mM}$ ) were also taken to perform further seeded growth at $25^{\circ} \mathrm{C}$ using the same amount and same concentration of $\mathrm{Ag}^{+}$-citrate solution mixture.

\section{Characterization}

All the samples were diluted twice and UV-vis absorption spectroscopy was performed on the Perkin Elmer Lambda 750 spectrophotometer. The sample preparation for transmission electron microscopy (TEM) was done by drop casting asprepared NCs on the carbon coated copper grids (Ted Pella, product code: 01800) and immediate drying of the grids in vacuum desiccators. TEM images were recorded on JEOL 2010 microscope at an operating voltage of $200 \mathrm{kV}$ to find the size, shape and structure of the NCs.

SERS of $\operatorname{Cr}(\mathrm{III})$ and $\mathrm{Cr}(\mathrm{vI})$ species. Raman spectroscopy was first performed by the addition of aqueous $\mathrm{Cr}$ (III) ion solution $(0.5 \mathrm{ppm})$ to the solution of both spherical Ag-412 NCs (plasmon peak at $412 \mathrm{~nm}$ ) and anisotropic Ag-790 NCs (plasmon peak at $790 \mathrm{~nm}$ ). Then the Raman spectra were again recorded by gradual addition of chromite ion to the solution of AIT NCs ([Hyd $]=40 \mathrm{mM}$, at pH 7 and $5{ }^{\circ} \mathrm{C}, 2^{\text {nd }} \mathrm{SPR} \lambda_{\max }$ at $550 \mathrm{~nm}$ ). The concentration of chromite anion was increased in the following order: $0.5 \rightarrow 1 \rightarrow 1.5 \rightarrow 2 \rightarrow 2.5 \mathrm{ppm}$. Thus a calibration curve was made. Like $\mathrm{Cr}(\mathrm{III})$ ion, SERS spectroscopy of $\mathrm{Cr}(\mathrm{VI})$ species was also recorded in a similar manner.

SERS experiments. Raman spectroscopy was carried out on Renishaw InVia Raman Microscope. All prepared samples were placed in a quartz cuvette, and excited by a $35 \mathrm{~mW} 633 \mathrm{~nm}$ laser. The typical acquisition time of a SERS spectrum was 25 seconds.

\section{Results and discussion}

Nanospheres, nanoplates and nanopyramids of silver were prepared by a single-step process described in our previous work, ${ }^{23}$ have been used as nucleation centres in this work with an objective to comprehend the influence of shape of seed NCs on the structural and optical properties of overgrown NCs. Efforts have also been made to understand the effect of growth environment i.e. temperature and hydrazine (reductant) and $\mathrm{Ag}^{+}$(metal ion precursor) concentration on the whole process.

\section{Effect of hydrazine concentration on seed mediated growth}

In a preliminary study, spherical $\mathrm{Ag}$ NCs, prepared using $2.5 \mathrm{mM}$ of hydrazine (addressed as seed NCs-2.5 in remaining sections), were taken and fixed amount of $\mathrm{Ag}^{+}$-Cit solution (aqueous solution of $\mathrm{Ag}^{+}$and citrate in the molar ratio of $1: 4$, where $\left[\mathrm{Ag}^{+}\right]=1 \mathrm{mM}$ ), was added to initiate the seed-mediated overgrowth.

As shown in UV-visible absorption spectra in Fig. 1a there is no change in peak profile except for a very small increase in the absorbance value. In contrast, if the same amount of $\mathrm{Ag}^{+}$-Cit solution is added to as-synthesized anisotropic NCs synthesized using varying stoichiometric excess of hydrazine, the $2^{\text {nd }}$ plasmon peak, the in-plane dipole oscillation, further red-shifts as evident in the UV-visible data in Fig. 1b-d. Different anisotropic seeds synthesized with different hydrazine concentration are addressed with their [Hyd] in further section and their absorption spectra are shown in Fig. 1b-d and S1 of ESI. $\dagger$ Table 1 is the guide to eye to analyze the extent of red shift in $2^{\text {nd }}$ SPR peak for different samples.

It indicates that no growth has taken place over the spherical seed NCs with limited hydrazine concentration. It also suggests that some excess hydrazine needs to be present to induce
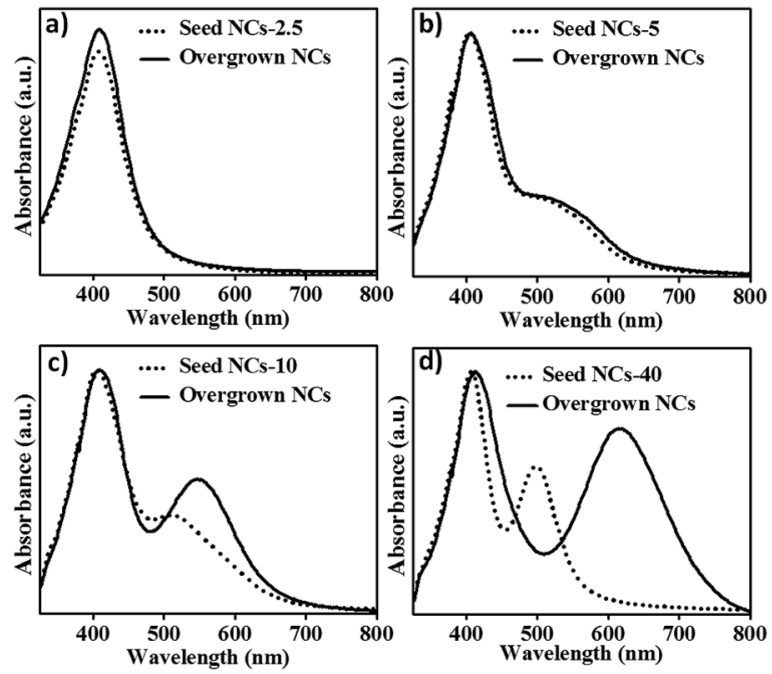

Fig. 1 UV-visible absorption spectra of different seed NCs (dotted line) prepared by varying the $[\mathrm{Hyd}]$ concentration $\left(\mathrm{C}_{\mathrm{Hyd}}\right)$ along with their respective NCs after overgrowth. (a) Spherical seed NCs $\left(C_{\text {Hyd }}: 2.5 \mathrm{mM}\right.$, SPR: $406 \mathrm{~nm}$ ) - spherical overgrown NCs (SPR-406), (b) anisotropic seed NCs $\left(C_{\text {Hyd }}: 5 \mathrm{mM}, 2^{\text {nd }}-\right.$ SPR: $\left.500 \mathrm{~nm}\right)$ - anisotropic overgrown NCs (2 $2^{\text {nd }}-$ SPR: $\left.511 \mathrm{~nm}\right),(c)$ anisotropic seed NCs $\left(C_{\text {Hyd }}: 10 \mathrm{mM}, 2^{\text {nd }}-\right.$ SPR: $502 \mathrm{~nm}$ ) - anisotropic overgrown NCs ( $2^{\text {nd }}-$ SPR: $\left.550 \mathrm{~nm}\right),(d)$ anisotropic seed NCs ( $C_{\text {Hyd }}: 40 \mathrm{mM}, 2^{\text {nd }}$ SPR: $\left.504 \mathrm{~nm}\right)$ - anisotropic overgrown NCs (2 ${ }^{\text {nd }}-$ SPR: $\left.615 \mathrm{~nm}\right)$.

Table $12^{\text {nd }}$ SPR peak for different anisotropic seed NCs and overgrown NCs with varying excess of hydrazine at fixed $\left[\mathrm{Ag}^{+}\right]=1 \mathrm{mM}$

\begin{tabular}{llll}
\hline $\begin{array}{l}{[\mathrm{Hyd}]} \\
(\mathrm{mM})\end{array}$ & $\begin{array}{l}2^{\text {nd }} \text { SPR peak of } \\
\text { seed NCs }(\mathrm{nm})\end{array}$ & $\begin{array}{l}2^{\text {nd }} \text { SPR peak of } \\
\text { overgrown NCs }(\mathrm{nm})\end{array}$ & $\begin{array}{l}\text { Red-shift of } 2^{\text {nd }} \\
\text { SPR peak }(\mathrm{nm})\end{array}$ \\
\hline 5 & 500 & 511 & 11 \\
10 & 502 & 550 & 48 \\
20 & 503 & 603 & 100 \\
40 & 504 & 615 & 111 \\
60 & 500 & 610 & 110 \\
80 & 500 & 605 & 105
\end{tabular}


anisotropic growth. As mentioned earlier, the as-prepared anisotropic seeds had an initial excess of hydrazine which could have caused anisotropic growth and hence red-shifts in SPR peaks are obtained to varying extent.

We further hypothesized that spherical seed NCs could also grow into anisotropic shapes if excess hydrazine is present. To verify this, a series of seed-mediated syntheses were performed by adding varying hydrazine concentration ([Hyd]) to the same solution of spherical seed NCs in which no anisotropic overgrowth was observed. As shown in Fig. 2a, all these overgrown NCs exhibit two SPR peaks that indicate formation of anisotropic NCs (other than spherical shape) which has been shown schematically in inset of Fig. 2a. It can also be seen that there is gradual red-shift in the second SPR peak, $545 \rightarrow 560 \rightarrow 570 \mathrm{~nm}$, with increasing hydrazine concentration ([Hyd]), $2.5 \rightarrow 5.0 \rightarrow$ 10.0 mM, respectively. This clearly shows that anisotropic overgrowth is driven by the excess hydrazine and larger is the amount of hydrazine, greater is the red-shift in the SPR peaks.

The high resolution TEM images (Fig. 2b-d) reveal that spherical seed NCs have been transformed into hexagonal platelike structures with an edge length $12 \mathrm{~nm}$. About $10 \mathrm{~nm}$ increase in the overall size of the overgrown NCs $(30 \mathrm{~nm})$ has been observed as compared to the seed NCs $(20 \mathrm{~nm})$. Further, from the closer view of the overgrown NCs, Fig. 2d, it can also be interpreted that the growth has taken place towards $\{111\}$ facets of NCs with $d$-value of $2.3 \AA$. Also, as discussed in our previous work ${ }^{23}$, [Hyd] is a crucial factor in determining the overall quality of plamonic NCs formed. It affects the growth process in two ways, (i) influencing rate of the reduction (ii) influencing the hydrogen-bonding interaction with citrate. Therefore, [Hyd] plays an important role in NCs growth as well as in postsynthetic over growth on a NC seed.

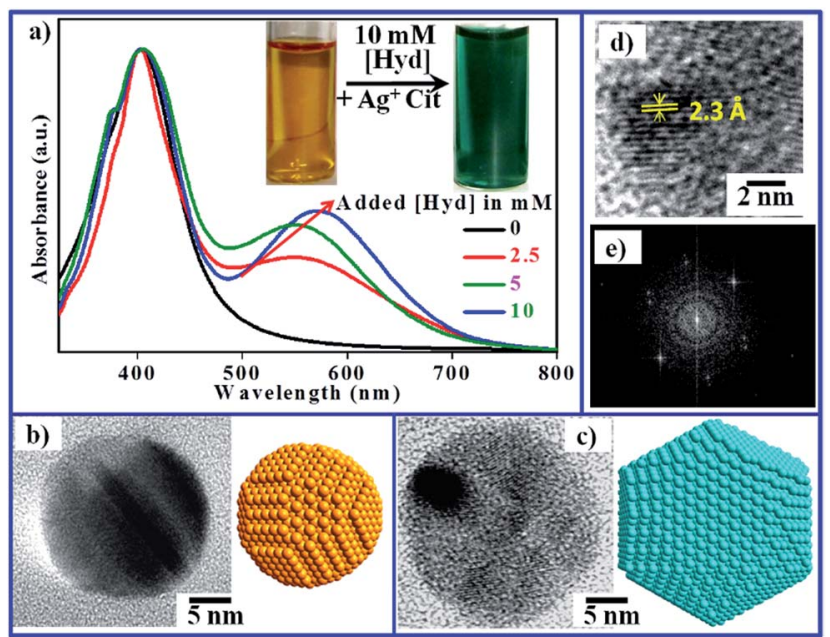

Fig. 2 (a) UV-visible absorption spectra of spherical NCs and overgrown nanocrystals obtained on addition of hydrazine hydrate in this order: $0 \mathrm{mM} \rightarrow 2.5 \mathrm{mM} \rightarrow 5 \mathrm{mM} \rightarrow 10 \mathrm{mM}$ (b) TEM image of spherical seed NCs. (c) TEM image of anisotropic NCs after overgrowth prepared by the addition of excess $10 \mathrm{mM}$ hydrazine. (d) HR-TEM image (zoomed-in view) showing the lattice fringes of $d: 2.3 \AA$. (e) FFT of the HR-TEM image. The TEM images and histogram showing size distribution of the seed NCs and overgrown NCs are given in Fig. S3a, $a^{\prime}, b$ and $b^{\prime} . \dagger$
Further, on analyzing the data given in Table 1, an interesting trend emerges. All the seed NCs have $2^{\text {nd }} \lambda_{\text {SPR }}$ at around $500 \mathrm{~nm}$, the amount of $\mathrm{Ag}^{+}$used in seed-mediated growth is also the same, but the extent of red-shift in $2^{\text {nd }}$ SPR $\lambda_{\max }$ for the overgrown NCs varies in a vast range from $11 \mathrm{~nm}$ to $111 \mathrm{~nm}$. For an 8 times increase in [Hyd] $(5 \rightarrow 40 \mathrm{mM})$, there is 10 times greater red-shift $(11 \rightarrow 111 \mathrm{~nm})$ in $2^{\text {nd }}$ SPR peak. Therefore, it is quite clear that plasmon tunability of the overgrown NCs is crucially dependent on hydrazine concentration.

\section{Stabilizer-reductant H-bonding and plasmonic tuning}

The cause of the aforementioned structural and plasmonic tuning is the hydrogen bonding (H-bonding) interaction between stabilizer and reductant. The H-bonding network that forms due to citrate-hydrazine interaction is the driving force for the anisotropic overgrowth of NCs. With increase in hydrazine concentration, the $\mathrm{H}$-bonded network around the seed NCs is strengthened and the constraints put forth do not allow the crystal to grow isotropically. Thus, it favours growth in the direction of lattice planes that have lower surface energy. The citrate hydrazine interaction was investigated by Raman spectroscopy and second derivative FTIR analysis. Fig. 3a shows the
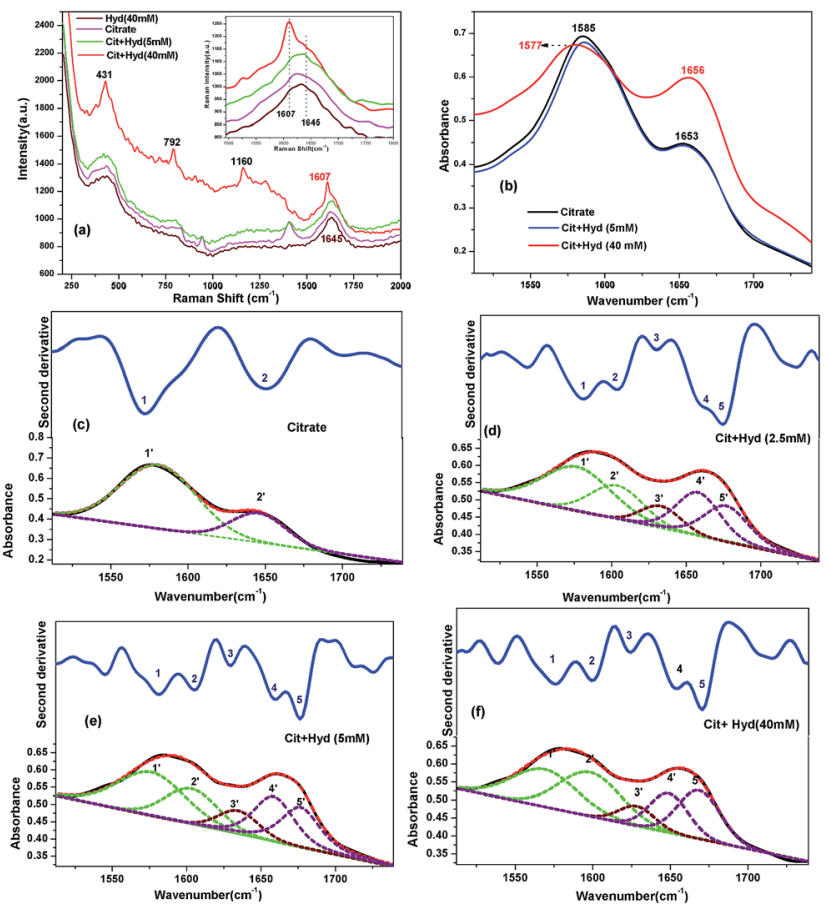

Fig. 3 (a) Raman spectra of pure citrate solution, pure hydrazine hydrate solution and their mixture with varying hydrazine concentrations $\left(\left[\mathrm{Ag}^{+}\right]=1 \mathrm{mM}, \mathrm{Ag}^{+}\right.$: Cit molar ratio, $\left.1: 4\right)$ (b) FTIR spectra of pure citrate, and the solution of citrate with varying hydrazine concentrations. Second derivative spectra and deconvolutions of FTIR peaks of pure citrate (c) and citrate mixed with varying concentrations of hydrazine: (d) $2.5 \mathrm{mM}$, (e) $5 \mathrm{mM}$ and (f) $40 \mathrm{mM}$ (- raw FTIR data, ......... and .... deconvoluted peaks, - overall fitting, - second derivative plot). \{band assignments of deconvolutions: $1,1^{\prime}$ - free $-\mathrm{COO}^{-}$asymmetric stretch; 2,2'-H-bonded - $\mathrm{COO}^{-}$asymmetric stretch; 3,3' 4,4' non-coordinated $\mathrm{H}_{2} \mathrm{O}$ deformation band; $5,5^{\prime}$ coordinated $\mathrm{H}_{2} \mathrm{O}$ deformation band\}. 
Raman spectra for pure hydrazine hydrate, pure citrate and the citrate-hydrazine mixture. The mixed solution having lower concentration of hydrazine, $5 \mathrm{mM}$, does not show much difference between the peak for citrate $\mathrm{COO}^{-}$asymmetric stretch $\left(1620 \mathrm{~cm}^{-1}\right)$ of pure citrate solution and citrate combined with $5 \mathrm{mM}$ hydrazine solution. However, as the hydrazine concentration is increased by 8 times to $40 \mathrm{mM}$, a significant change can be seen in the Raman spectra of mixed solution. It can be seen that the carboxylic asymmetric stretch splits into two vibration modes, one at comparatively lower energy side $\left(1607 \mathrm{~cm}^{-1}\right)$ and another at higher energy side $\left(1645 \mathrm{~cm}^{-1}\right)$. The new peak at $1607 \mathrm{~cm}^{-1}$ could be attributed to $\mathrm{H}$-bonding interaction between citrate and hydrazine. Apart from the asymmetric stretching mode, some changes in the $\mathrm{COO}^{-}$deformation band $\left(431,1160 \mathrm{~cm}^{-1}\right)$ of citrate ${ }^{23}$ have also been observed at high concentration of hydrazine $(40 \mathrm{mM})$ which also suggest strengthening of hydrogen bonded network. Similar observations were also made in FTIR spectroscopy (Fig. 3b). The citrate $\mathrm{COO}^{-}$asymmetric stretch appears at $1586 \mathrm{~cm}^{-1}$, which redshifts by $8 \mathrm{~cm}^{-1}$ on addition of $40 \mathrm{mM}$ hydrazine. Further insights into the hydrazine-citrate interactions is obtained by performing a rigorous second derivative analysis on FTIR spectra and the peaks were deconvoluted into several Gaussian functions. As shown in Fig. 3c-f, two new peaks appear on hydrazine addition to citrate at $\mathrm{pH} 5$, which were not initially present in the FTIR spectra of either citrate or hydrazine alone. The peak 2,2 appears at $1605 \mathrm{~cm}^{-1}$ which can be attributed to $\mathrm{H}$-bonded $\mathrm{COO}^{-}$vibrations. It should be noted that the same vibrational feature was seen in the Raman spectra at $1607 \mathrm{~cm}^{-1}$. It also shows how second derivative analysis reveals finer details which is not so apparent in the raw FTIR spectra. There is a linear rise in the relative intensity of this peak [ratio of peaks $\left.\left(2,2^{\prime}\right) /\left(1,1^{\prime}\right)\right]$ from 0.4 to 0.9 as the concentration of hydrazine is raised gradually from $2.5 \mathrm{mM}$ to $40 \mathrm{mM}$ (Fig. 4a). The hydrogen bonding interactions lead to versatile tunability of plasmon peaks from $500 \mathrm{~nm}$ to $615 \mathrm{~nm}$. As can be seen in Fig. $4 \mathrm{~b}$, a good correlation has been obtained between the plasmon peak position and the relative intensity of $\mathrm{H}$-bonded $\mathrm{COO}^{-}$peaks. Thus, a link between $\mathrm{H}$-bonding interaction and plasmon tunability has been clearly established.

\section{Effect of $\left[\mathrm{Ag}^{+}\right]$on seed mediated growth}

As discussed above, $1 \mathrm{mM}$ of $\mathrm{Ag}^{+}$has been used for seeded growth in each case. To analyze the role in detail, solutions
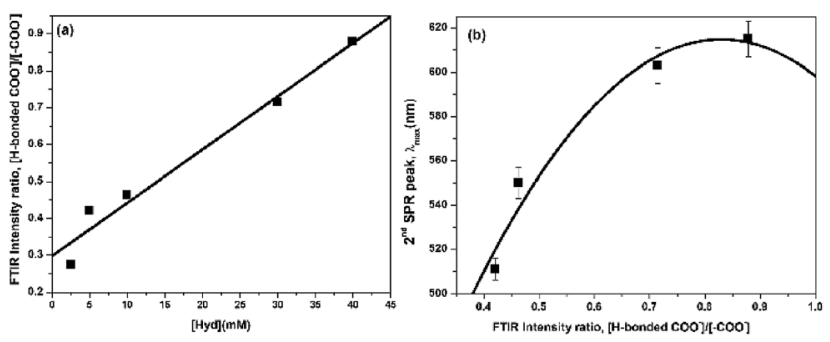

Fig. 4 (a) Variation of FTIR intensity ratio, [H-bonded $\left.\mathrm{COO}^{-}\right]:\left[\mathrm{COO}^{-}\right]$, with change in hydrazine hydrate concentration. (b) Variation of plasmon peaks with increase in relative intensity of $\mathrm{H}$-bonded $\mathrm{COO}^{-}$.

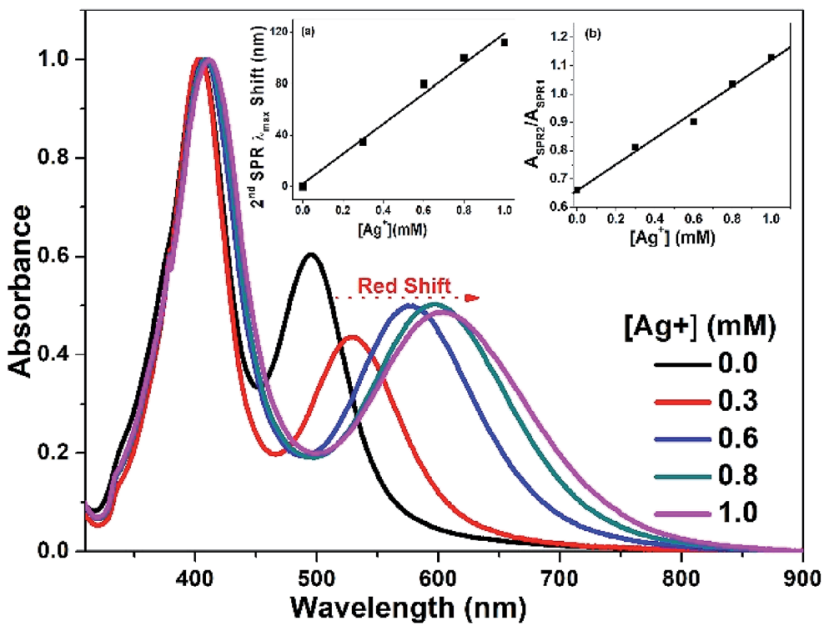

Fig. 5 UV-visible spectra showing the effect of $\mathrm{Ag}^{+}$ion concentration on the seed anisotropic NCs ( $C_{\text {Hyd }}: 40 \mathrm{mM}, 2^{\text {nd }}$ SPR: $\left.504 \mathrm{~nm}\right)$ during seeded growth at room temperature and $\mathrm{pH} 7$ (inset (a) $2^{\text {nd }}-\mathrm{SPR}$ position as function of $\mathrm{Ag}^{+}$ion; inset (b) relative intensity of $2^{\text {nd }}$ SPR peak).

having different $\mathrm{Ag}^{+}$concentrations, $0.3 \rightarrow 0.6 \rightarrow 0.8 \rightarrow$ $1.0 \mathrm{mM}$, were added separately to the same anisotropic seed NCs solution ( $2^{\text {nd }} \mathrm{SPR} \lambda_{\max }$ at $495 \mathrm{~nm}$ ). Influence of $\left[\mathrm{Ag}^{+}\right]$is quite evident in UV-visible absorption spectra (Fig. 5) that shows a gradual red shift in $2^{\text {nd }}$ SPR band from $529 \mathrm{~nm}$ to $608 \mathrm{~nm}$. A linear relationship has been obtained between the $2^{\text {nd }}$ SPR peak position and $\mathrm{Ag}^{+}$concentration (inset (a) of Fig. 5). The most red-shifted peak has been observed for $1 \mathrm{mM} \mathrm{Ag}^{+}$ion concentration. So, this concentration is optimized for the entire seeded growth experiments. Moreover, $2^{\text {nd }}$ SPR peak becomes more and more intense till the added $\left[\mathrm{Ag}^{+}\right]$reaches $1 \mathrm{mM}$. The ratio of integrated SPR intensities, $A_{\mathrm{SPR} 2} / A_{\mathrm{SPR} 1}$, varies linearly with the increasing $\mathrm{Ag}^{+}$concentration (inset (b), Fig. 5). So, the increase in $\mathrm{Ag}^{+}$concentration leads to a linear increase in both the aspects of SPR peak, the wavelength $\left(\lambda_{\max }\right)$ and the intensity.

\section{Effect of temperature on seed-mediated growth}

The effect of temperature can be clearly seen in Fig. 6a. Two sets of seed NCs were prepared, one at room temperature $\left(25^{\circ} \mathrm{C}\right)$, designated as Ag-504 seed NCs and the other one prepared at low temperature $\left(5^{\circ} \mathrm{C}\right)$ designated as Ag-550 seed NCs. The Ag504 seed NCs exhibit second plasmon peak at $504 \mathrm{~nm}$ which red-shifts to $590 \mathrm{~nm}$ for overgrown NCs (designated as Ag-590) on carrying out the growth at room temperature $\left(25^{\circ} \mathrm{C}\right)$. In contrast, overgrowth at low temperature $\left(5{ }^{\circ} \mathrm{C}\right)$ results in a redshift to $575 \mathrm{~nm}$ (overgrown NCs are designated as Ag-575). It is quite evident that the room temperature overgrowth leads to a larger red shift (86 $\mathrm{nm}$ ) as compared to overgrowth at low temperature $\left(5^{\circ} \mathrm{C}\right)$ which gives a redshift of $71 \mathrm{~nm}$.

A similar pattern can be seen for the Ag-550 seed NCs which had the $2^{\text {nd }}$ SPR peak at $550 \mathrm{~nm}$. The peak red-shifts to $610 \mathrm{~nm}$ if the seeded overgrowth is conducted at low temperature. i.e., $5{ }^{\circ} \mathrm{C}$ (overgrown NCs designated as Ag-610). A larger red shift of $90 \mathrm{~nm}(550 \mathrm{~nm} \rightarrow 640 \mathrm{~nm})$ is observed on carrying out the 


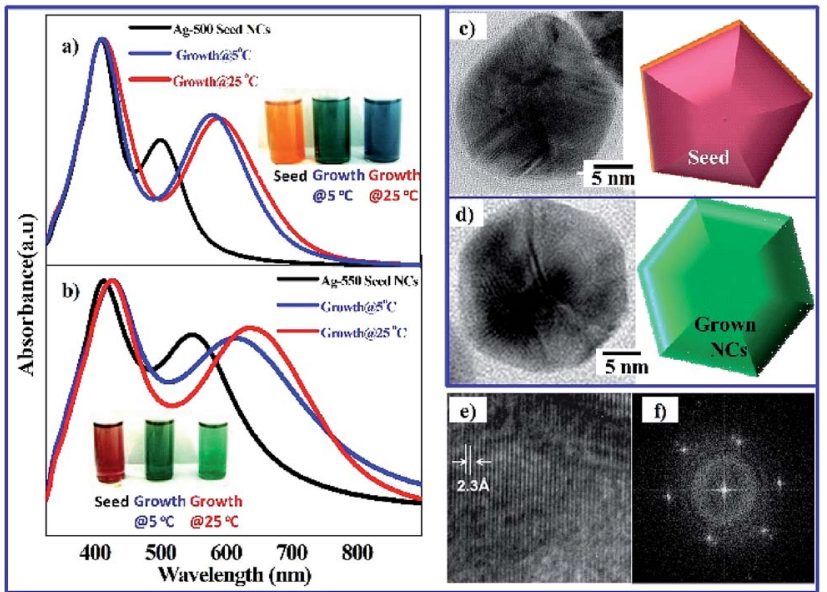

Fig. 6 (a) UV-visible spectra of Ag-504 seed NCs (at $25^{\circ} \mathrm{C}, \mathrm{pH} 7$ $C_{\text {Hyd }}=40 \mathrm{mM}, 2^{\text {nd }}-\mathrm{SPR}$ at $504 \mathrm{~nm}$ ) along with anisotropic NCs after overgrowth at two different temp. $\left(25^{\circ} \mathrm{C}\right.$ and $\left.5{ }^{\circ} \mathrm{C}\right)$. (b) UV-visible spectra of $\mathrm{Ag}-550 \mathrm{NCs}\left(\right.$ at $5^{\circ} \mathrm{C}, \mathrm{pH} 7, \mathrm{C}_{\text {Hyd }}=40 \mathrm{mM}, 2^{\text {nd }}-\mathrm{SPR}$ at 550 $\mathrm{nm})$ along with after overgrowth at two different temp. $\left(25^{\circ} \mathrm{C}\right.$ and 5 ${ }^{\circ} \mathrm{C}$ ). (c,d) TEM images of seed anisotropic NCs (at $5{ }^{\circ} \mathrm{C}, \mathrm{pH} 7, \mathrm{C}_{\mathrm{Hyd}}=$ $40 \mathrm{mM}, 2^{\text {nd }}$-SPR at $550 \mathrm{~nm}$ ) and NCs after overgrowth at $25^{\circ} \mathrm{C}$. (e) High resolution (zoomed-in view) reveals the lattice fringes of $d: 2.3 \AA$. (f) FFT pattern. The TEM images and histogram showing size distribution of the seed NCs and overgrown NCs are given in Fig. S3c, $c^{\prime}$, $d$ and $d^{\prime} \cdot \dagger$

growth at room temperature (overgrown NCs designated as Ag640).

Thus, the two results corroborate each other and it can be inferred that room temperature overgrowth vis-à-vis low temperature one is best suited for synthesis of anisotropic NCs with maximum red-shifted plasmon peak. This is in contrast to the seed-less, single step synthesis in which better SPR tunability was achieved at low temperature as discussed in our previous work. ${ }^{23}$ Although citrate-hydrazine H-bonding plays a crucial role in both the approaches, the observation suggests that the mechanism of growth could be different in two cases. In seed mediated synthesis, it is the room temperature growth that induces greater structural anisotropy and hence greater red-shift in the SPR peak is obtained.

The structural anisotropy of the seed and overgrown NCs was analyzed by HRTEM images (Fig. $6 \mathrm{c}$ and d). It reveals that the anisotropic pentagonal plate like Ag-550 seed NCs have been transformed to hexagonal plate like NCs during the room temperature overgrowth (Ag-640). The change in structure resulted in the red shift of second plasmon peak (550 nm $\rightarrow 640$ $\mathrm{nm})$.

The structural transformation (pentagonal $\rightarrow$ hexagonal) also accompanied with an increase in size from $40 \mathrm{~nm}$ to $47 \mathrm{~nm}$ along with a change in edge length for the overgrown NCs. The overgrown NCs (hexagonal plates) have six edges of $15 \mathrm{~nm}$ each while then seed NCs (pentagonal plates) have three edges of $25 \mathrm{~nm}$ each and the other two of $15 \mathrm{~nm}$ each. Closer view of HRTEM image of overgrown NCs shows that the growth has taken place towards $\{111\}$ facets with an interplanar spacing of $2.3 \AA$ (Fig. 6e).

\section{Effect of shape of seed}

As discussed in previous sections, spherical seed NCs as well as plate-like seed NCs result in formation of anisotropic NCs with red-shifted SPR peak after overgrowth. To further understand the influence of shape of seed NCs, synthesis was carried out using pyramid like Ag NCs (designated as Ag-790 seed NCs) as the nucleation centres (seed). Surprisingly, a blue shift of $15 \mathrm{~nm}$ $(790 \mathrm{~nm} \rightarrow 775 \mathrm{~nm})$ in $2^{\text {nd }}$ SPR peak was observed for the overgrown NCs (Fig. 7a) which is in contrast to all the previous results. Here, it can be noted that the change in geometry of seed NCs i.e. from plate-like to pyramid like structure, reverses the trend of plasmon tunability. A comparison of the HRTEM images (Fig. 7b and c) reveals that overall size of NCs increases from $30 \mathrm{~nm}$ to $45 \mathrm{~nm}$. Furthermore, the seed NCs are clearly faceted with sharp edges and corners, but the overgrown NCs do not possess such sharp facets although the overall shape remains pyramid-like. So, there is some loss of structural anisotropy and a shift towards more symmetry which leads to the blue-shift as well as enhancement of plasmon peak intensity.

\section{SERS spectroscopic detection of $\mathrm{Cr}(\mathrm{III})$ and $\mathrm{Cr}(\mathrm{VI})$}

To realize the potentials of the as-prepared Ag NCs in SERSbased detection of toxic metal ions, experiments were performed with Ag-412, the spherical NCs and Ag-790, the

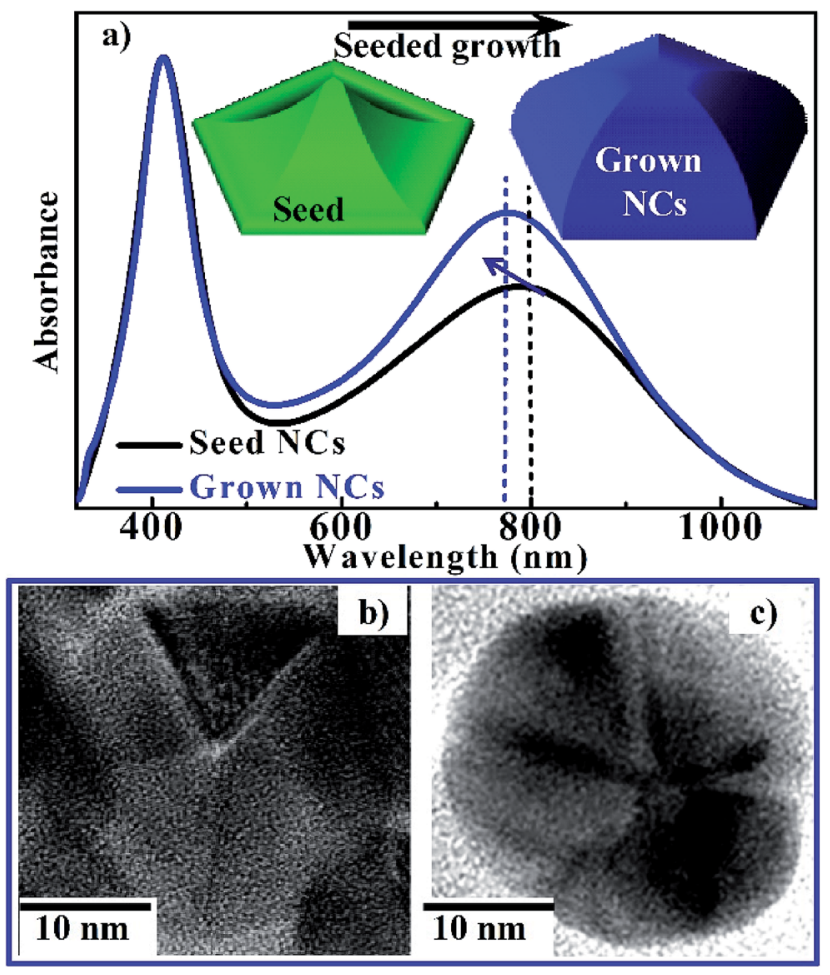

Fig. 7 (a) Absorption spectra of Ag-790 anisotropic seed NCs and the overgrown nanocrystals. HR-TEM images of (b) Ag-790 anisotropic $\mathrm{NCs}\left(C_{\mathrm{Hyd}}=40 \mathrm{mM}\right.$, at pH 5 \& $5{ }^{\circ} \mathrm{C}, 2^{\text {nd }}-\mathrm{SPR}$ at $\left.790 \mathrm{~nm}\right)$ and (c) NCs after overgrowth $\left(2^{\text {nd }}-\right.$ SPR at $\left.775 \mathrm{~nm}\right)$. The TEM images showing size distribution of the seed NCs and overgrown NCs are given in Fig. S3e, $e^{\prime}, f$ and $f^{\prime} . \dagger$ 
anisotropic pyramid-like NCs in non-resonant condition using $633 \mathrm{~nm}$ laser. SERS spectroscopy was performed for $\mathrm{Cr}$ in two different oxidation states, $\mathrm{Cr}(\mathrm{III})$ and $\mathrm{Cr}(\mathrm{VI})$ by taking solutions of $\mathrm{Cr}_{2} \mathrm{O}_{3}$ and $\mathrm{Cr}_{2} \mathrm{O}_{7}{ }^{2-}$. No enhancement was observed if spherical $\mathrm{Ag}$ NCs are used. In contrast, on using Ag-790 anisotropic NCs, the Raman intensity of stretch mode of chromite $(\mathrm{Cr}(\mathrm{III})-\mathrm{O}$ stretch) at $533 \mathrm{~cm}^{-1}$ was enhanced even at an ultralow concentration of $0.1 \mathrm{ppm}$ (Fig. 8). Further, as the concentration of $\mathrm{Cr}(\mathrm{III})$ is increased, the Raman intensity increases gradually. The SERS signal and $\left[\mathrm{Cr}^{3+}\right]$ show a good linear relationship as shown in inset of Fig. 8 a. This plot of Raman intensity $v s .\left[\mathrm{Cr}^{3+}\right]$ can act as a calibration curve using which unknown $\operatorname{Cr}($ III) in a test-sample can be determined. The equation of the regression line is given in the Table 2. The limit of detection was found to be $30 \mathrm{ppb}$. In a similar manner, solution phase SERS spectroscopy of $\mathrm{Cr}(\mathrm{vI})$ species was also done using Ag-790 NCs, results of which is shown in Fig. 8b. The Raman peak for the $\mathrm{Cr}(\mathrm{vI})-\mathrm{O}$ stretch mode appears at $841 \mathrm{~cm}^{-1}$, which increases linearly with the increasing concentration of $\mathrm{Cr}(\mathrm{vI})$ species in the solution (inset of Fig. 8b). Although the plots are linear in each case, the
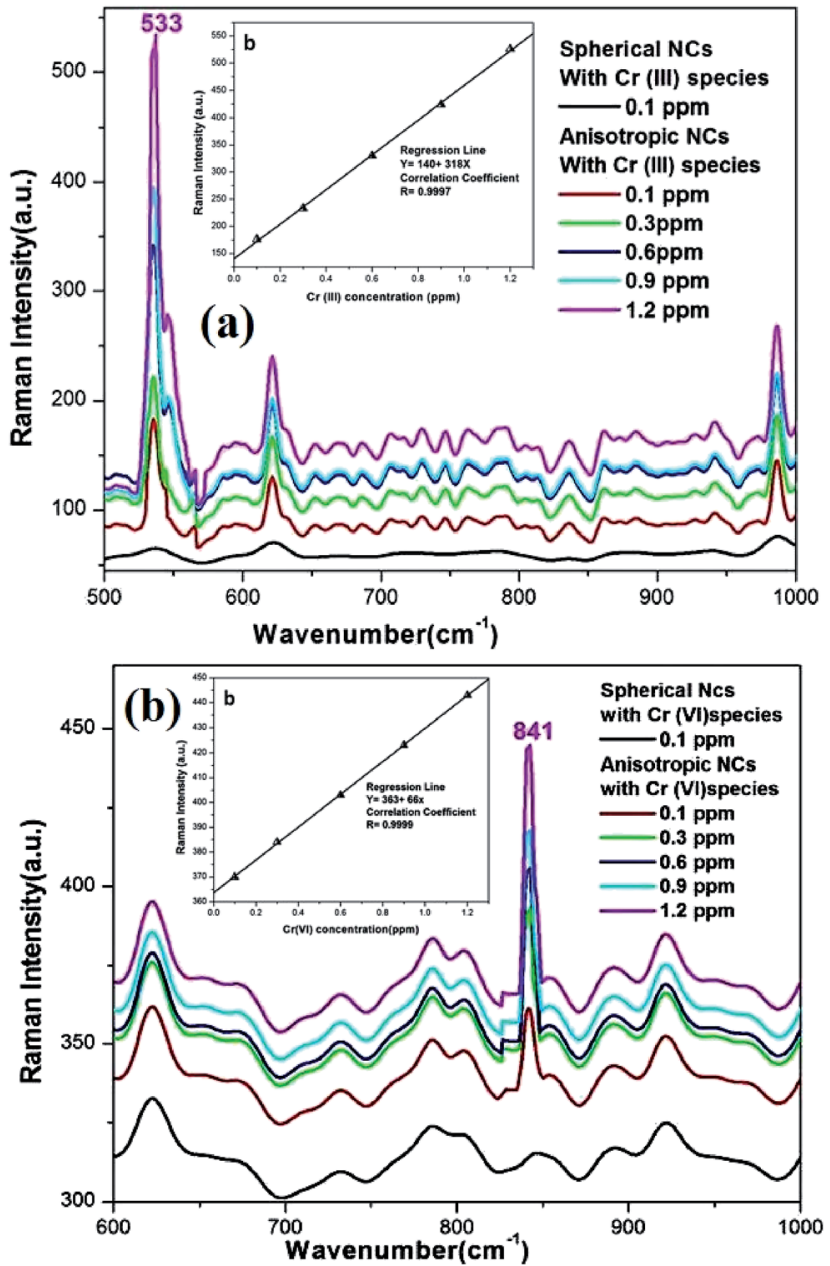

Fig. 8 SERS spectra showing the responses for both (a) $\mathrm{Cr}$ (III) and (b) $\mathrm{Cr}(\mathrm{VI})$ ions using $\mathrm{Ag}-790 \mathrm{NCs}$. The concentration order: $0.1 \rightarrow 0.3 \rightarrow$ $0.6 \rightarrow 0.9 \rightarrow 1.2 \mathrm{ppm}$. Inset view: linear increase in Raman intensity with the increase in concentration of both $\mathrm{Cr}(\mathrm{III})$ and $\mathrm{Cr}(\mathrm{VI})$.
Table 2 The details of regression line fittings for the SERS-based detection of different oxoanions using anisotropic silver nanocrystals

\begin{tabular}{llll}
\hline $\begin{array}{l}\text { Metallic } \\
\text { species }\end{array}$ & $\begin{array}{l}\text { Equation of } \\
\text { regression line }\end{array}$ & $\begin{array}{l}\text { Coefficient of } \\
\text { correlation, } R\end{array}$ & $\begin{array}{l}\text { Limit of detection } \\
Y_{\text {lod }}(\mathrm{ppb})\end{array}$ \\
\hline $\mathrm{Cr}(\mathrm{III})$ & $Y=140+318 X$ & 0.9997 & 30 \\
$\mathrm{Cr}(\mathrm{VI})$ & $Y=363+66 X$ & 0.9999 & 40
\end{tabular}

sensitivity is different. The slope of the curve $(\mathrm{d} I / \mathrm{d} c)$ gives a measure of sensitivity and on comparison of these values, 318 for $\mathrm{Cr}(\mathrm{III})$ and 66 for $\mathrm{Cr}(\mathrm{VI})$, we find that the detection would be most-sensitive for $\mathrm{Cr}(\mathrm{III})$ species. The detection limit for $\mathrm{Cr}(\mathrm{VI})$ was found to be $40 \mathrm{ppb}$. We also note that all these peaks are well separated in SERS spectra and therefore simultaneous determination of all the two species, $(\mathrm{Cr}(\mathrm{III})$ and $\mathrm{Cr}(\mathrm{VII}))$, present in water is also possible. Furthermore, our limit of detection (30 and $40 \mathrm{ppb}$ for $\mathrm{Cr}-\mathrm{III}$ and $\mathrm{Cr}-\mathrm{VI}$, respectively) is one order lower than the permissible limit of total chromium in the drinking water $(0.1 \mathrm{ppm})$ as prescribed by the US EPA (United States Environment Protection Agency). ${ }^{46}$ Thus, the findings will have strong implications in developing SERS based sensors for inorganic contaminants commonly found in groundwater and some biological systems.

\section{Conclusions}

In summary, a novel seed-mediated growth of anisotropic Ag NCs has been developed by altering the H-bonding interaction of mild stabilizer-reductant (citrate-hydrazine) system. The influence of shape of seed NCs has been thoroughly investigated. The nucleation with spherical seed NCs yields anisotropic NCs having highly tunable newly emerged $2^{\text {nd }}$ SPR band. Interestingly, the overgrowth with anisotropic seed NCs may result in either a red-shift or blue-shift of plasmon peak depending on the geometry of seed NCs. The red-shift is attributed to shape transformation from pentagonal to hexagonal plate-like NCs whereas the blue-shift is due to reduced structural anisotropy of the overgrown NCs. Room temperature overgrowth vis-à-vis low temperature one was found to bring about greater redshift in plasmon peak. Furthermore, based on the SERS enhancement for oxoanions of $\mathrm{Cr}(\mathrm{III})$ and $\mathrm{Cr}(\mathrm{VI})$ species, a simple, yet sensitive spectroscopic method for the detection of these ions has been developed using anisotropic silver NCs. Amongst the two inorganic species, maximum enhancement of SERS signal has been achieved for Cr(III) which translates to lowest detection limit of $30 \mathrm{ppb}$. The findings would assist in future design of plasmonic nanostructures with specific geometrical features suitable for the development of novel SERS based nanosensors and nano-theranostic tools.

\section{Conflicts of interest}

There are no conflicts of interest to declare. 


\section{Acknowledgements}

A. P. gratefully acknowledges the financial support from Dept. of Science and Technology, Govt. of India, for research funding through grant number SR/NM/NS-1047/2012 and SB/FT/CS-84/ 2011. One of the authors (S. P.) is thankful to Birla Institute of Technology, Mesra for the award of the institute's fellowship. One of the authors (A. S.) thanks DST, Govt of India for KVPY fellowship. The authors thank all the staff of Central Instrumentation Facility, BIT Mesra, for their help in various instrumental measurements. Authors also thank Dr Rishi Sharma, Dept. of Applied Physics for Raman spectroscopic measurements.

\section{Notes and references}

1 I. D. Mayergoyz, Plasmon Resonances in Nanoparticles, World Scientific, Singapore, 2013; N. S. Lewis, Chem. Rev., 1993, 93, 2693-2730.

2 A. Trügler, Optical Properties of Metallic Nanoparticles: Basic Principles and Simulation, Springer, Heidelberg (Germany), 2016; G. Schmid, Cluster and Colloids: From Theory to Applications, Wiley-VCH, New York, 1994.

$3 \mathrm{M}$. Pelton and G. W. Bryant, Introduction to MetalNanoparticle Plasmonics, John Wiley \& Sons, Hoboken, NJ (USA), 2013; A. Henglein, J. Phys. Chem., 1993, 97, 5457-5471. 4 Y.-T. Long and C. Jing, Localized Surface Plasmon Resonance Based Nanobiosensors, Springer, Heidelberg (Germany), 2014; J. Belloni, Curr. Opin. Colloid Interface Sci., 1996, 1, 184-196.

5 E. I. Alarcon, M. Griffith and K. I. Udekwu, Silver Nanoparticle Applications, Springer, 2015; S. W. Chen, R. S. Ingram, M. J. Hostetler, J. J. Pietron, R. W. Murray, T. G. Schaaff, J. T. Khoury, M. M. Alvarez and R. L. Whetten, Science, 1998, 280, 2098-2101.

6 A. Priyam, N. M. Idris and Y. Zhang, J. Mater. Chem., 2012, 22, 960-965; S.-R. Gou, J.-Y. Gong, P. Jiang, M. Wu, Y. Lu and S.-H. Yu, Adv. Funct. Mater., 2008, 18, 872-879.

7 A. Ben-Yakar, D. S. Eversole and O. Ekici, in Non-Magnetic Metallic Nanomaterials for Life Sciences, ed. C. Kumar, John Wiley \& Sons, Weinheim, 2008, pp. 493-539.

8 X. Huang, I. H. El-Sayed, W. Qian and M. A. El-Sayed, J. Am. Chem. Soc., 2006, 128, 2115-2120.

9 X. Huang, P. K. Jain, I. H. El-Sayed and M. A. Ei-Sayed, Nanomedicine, 2007, 2, 681-693.

10 Y. Zhou, Y. Kong, S. Kundu, J. D. Cirillo and H. Liang, J. Nanobiotechnol., 2012, 10, 1-9.

11 S. Shamaila, N. Zafar, S. Riaz, R. Sharif, J. Nazir and S. Naseem, Nanomaterials, 2016, 6, 71.

12 M. A. Raza, Z. Kanwal, A. Rauf, A. N. Sabri, S. Riaz and S. Naseem, Nanomaterials, 2016, 6, 74.

13 M. Murdoch, G. I. N. Waterhouse, M. A. Nadeem, J. B. Meston, M. A. Keane, R. F. Howe, J. Liorca and H. Idriss, Nat. Chem., 2011, 3, 489-492.

14 A. J. Haes and R. P. van Duyne, J. Am. Chem. Soc., 2002, 124, 10596-10604.

15 J.-M. Nam, C. S. Thaxton and C. A. Mirkin, Science, 2003, 301, 1884-1886.
16 Z. Guo, G. Chen, G. Zeng, Z. Li, A. Chen, M. Yan, L. Liu and D. Huang, RSC Adv., 2014, 4, 59275.

17 W. Haoran, S.-M. H. Abtahi and P.-J. Vikesland, Environ. Sci.: Nano, 2015, 2, 120-135.

18 S. A. Maier, P. G. Kik, H. A. Atwater, S. Meltzer, E. Harel, B. E. Koel and A. A. G. Requicha, Nat. Mater., 2003, 2, 229232.

19 R. A. Shelby, D. R. Smith and S. Schultz, Science, 2001, 292, 77-78.

20 (a) D. I. Gittins, D. Bethell, D. J. Schiffrin and R. J. Nichols, Nature, 2000, 408, 67-69; (b) L. Shen, L. Du, S. Tan, Z. Zang, C. Zhao and W. Mai, Chem. Commun., 2016, 52, 6296-6299.

21 R. G. Freeman, K. C. Grabar, K. J. Allison, R. M. Bright, J. A. Davis, A. P. Guthrie, M. B. Hommer, M. A. Jackson, P. C. Smith, D. G. Walter and M. J. Natan, Science, 1995, 267, 1629-1632.

22 Electromagnetic mechanism of surface-enhanced spectroscopy, ed. G. C. Schatz and R. P. Van Duyne, Wiley, New York, 2002, pp. 759-774.

23 S. Pattanayak, A. Swarnkar, A. Priyam and G. M. Bhalerao, Dalton Trans., 2014, 43, 11826-11833.

24 S. Link and M. A. El-Sayed, J. Phys. Chem. B, 1999, 103, 84108426.

25 S. Agnihotri, S. Mukherji and S. Mukherji, RSC Adv., 2014, 4, 3974-3983.

26 S. Eustis and M. A. El-Sayed, Chem. Soc. Rev., 2006, 35, 209217.

27 X. Lu, M. Rycenga, S. E. Skrabalak, B. Wiley and Y. Xia, Annu. Rev. Phys. Chem., 2009, 60, 167-192; M. Rycenga, C. M. Cobley, J. Zeng, W. Li, C. H. Moran, Q. Zhang, D. Qin and Y. Xia, Chem. Rev., 2011, 111, 3669-3712.

28 B. Nikoobakht and M. A. El-Sayed, Chem. Mater., 2003, 15, 1957-1962.

29 P. Yu, J. Huang and J. Tang, Nanoscale Res. Lett., 2011, 6, 4652.

30 J. An, B. Tang, X. Ning, J. Zhou, S. Xu, B. Zhao, W. Xu, C. Corredor and J. R. Lombardi, J. Phys. Chem. C, 2007, 111, 18055-18059.

31 A. R. Tao, S. Habas and P. Yang, Small, 2008, 4, 310-325.

32 P. C. Angelome, H. H. Mezerji, B. Goris, I. Pastoriza-Santos, J. Pérez-Juste, S. Bals and L. M. Liz-Marzán, Chem. Mater., 2012, 24, 1393-1399.

33 X. Dong, X. Xi, H. Wu, L. Zhao, J. Li and W. Yang, J. Phys. Chem. C, 2009, 113, 6573-6576.

34 N. R. Jana, L. Gearheart and C. J. Murphy, J. Phys. Chem. B, 2001, 105, 4065-4067.

35 G. Kawamura, Y. Yang and M. Nogami, J. Phys. Chem. C, 2008, 112, 10632-10636.

36 B. J. Wiley, Y. Chen, J. M. McLellan, Y. Xiong, Z. Y. Li, D. Ginger and Y. Xia, Nano Lett., 2007, 7, 1032-1036.

37 S. Yang, T. Zhang, L. Zhang, S. Wang, Z. Yang and B. Ding, Colloids Surf., A, 2007, 296, 37-44.

38 J. Zhu, Y. She, A. Xie, L. Qiu, Q. Zhang and S. Zhang, J. Phys. Chem. C, 2007, 111, 7629-7633.

39 J. Zhang, M. R. Langille and C. A. Mirkin, Nano Lett., 2011, 11, 2495-2498. 
40 J. Zhang, M. R. Langille and C. A. Mirkin, J. Am. Chem. Soc., 2010, 132, 12502-12510.

41 X. Xia, J. Zeng, Q. Zhang, H. C. Moran and Y. Xia, J. Phys. Chem. C, 2012, 116, 21647-21656; A. R. Tao, S. Habas and P. Yang, Small, 2008, 4, 310-325.

42 Z. Xu, J. Hao, F. Li and X. Meng, J. Colloid Interface Sci., 2010, 347, 90-95.

43 M. Mulvihill, A. Tao, K. Benjauthrit, J. Arnold and P. Yang, Angew. Chem., Int. Ed., 2008, 120, 6556-6560.
$44 \mathrm{~J} . \mathrm{Li}, \mathrm{L}$. Chen, T. Lou and Y. Wang, ACS Appl. Mater. Interfaces, 2011, 3, 3936-3941.

45 S. P. Ravindranath, K. L. Henne, D. K. Thompson and J. Irudayaraj, ACS Nano, 2011, 5, 4729-4736; Y. Ye, H. Liu, L. Yang and J. Liu, Nanoscale, 2012, 4, 6442-6448.

46 National Primary Drinking Water Regulations, https:// www.epa.gov/ground-water-and-drinking-water/nationalprimary-drinking-water-regulations\#two, accessed July 2017. 